\title{
Detection of Virtually All Mutations-SSCP (DOVAM-S): A Rapid Method for Mutation Scanning with Virtually $100 \%$ Sensitivity
}

BioTechniques 26:932-942 (May 1999)

Q. Liu, J. Feng, C. Buzin, C. Wen, G. Nozari, A. Mengos, V. Nguyen, J. Liu, L. Crawford, F.K. Fujimura and S.S. Sommer City of Hope National Medical Center, Duarte, CA, USA

\footnotetext{
ABSTRACT

Dideoxy fingerprinting (ddF) was used as a tool to search for a generic set of conditions with sufficient power to detect virtually all mutations. For each condition test$e d$, a very large sample of mutation-containing, single-stranded segments (about 1500) were analyzed with ddF. Correlation coefficients identified pairs of conditions in which single-strand conformation polymorphism (SSCP) mobilities were poorly correlated. The data strongly suggest that tertiary structure (e.g., base-sugar and sugar-sugar interactions) rather than secondary structure is the predominant determinant of mobility shifts by SSCP. Five conditions were selected with sufficient redundancy to detect all the mutations. The sensitivity of detection of virtually all mutations-SSCP (DOVAM-S) was determined by blinded analyses on samples containing additional mutations scattered throughout the eight exons and splice junctions in the factor IX gene. The factor IX gene sequence $(2.5 \mathrm{~kb})$ was scanned in one lane by 15 PCR-amplified segments (125 kb of sequence scanned per gel). All of the 84 single-base substitutions were detected in the blinded analyses, the first consisting of 50 hemizygous mutant and wild-type (WT) samples and the second consisting of 50 heterozygous mutant and WT samples. DOVAM-S is estimated to be five times faster than fluorescent DNA sequencing for the detection of virtually all mutations when the five conditions are applied.
}

\section{INTRODUCTION}

Single-strand conformation polymorphism (SSCP) is the most widely used method for mutation scanning. With SSCP, single-base sequence changes can be detected by altered electrophoretic migration of one or both single strands on a non-denaturing gel. SSCP does not detect all sequence changes with one electrophoresis condition, and its sensitivity is a complex function of sequence context and size (1-3,6,8-12).

Previous work suggested that the idiosyncratic nature of SSCP sensitivity is a function of both the distribution of mobility of single-base changes and the mobility of the wild-type (WT) sequences relative to that of all singlebase changes (Figure 1). For a 200-bp segment, there are 600 possible variants that differ by a single base substitution. If it were possible to generate all 600 possible variants and to plot the mobility in units of band widths, it is apparent that the sensitivity of SSCP will be less for a segment in which the mobility of the WT sequence is close to the mode (Figure 1A). If the variance of mobility is wider (Figure 1B), SSCP sensitivity, on average, will be higher than with the first condition. However, this is not necessarily so, because the location of the WT sequence within the distribution is also critical.

At least two ways to increase the sensitivity of SSCP have been described. In one approach, SSCP is hybridized with another method in order to generate the redundancy of mutation-containing segments necessary to detect virtually all mutations. For example, in dideoxy fingerprinting (ddF), SSCP is combined with Sanger dideoxy sequencing $(6,9)$. A Sanger dide- oxy termination reaction is performed with one dideoxy terminator. The terminated single-stranded segments are electrophoresed through a non-denaturing gel. The ladder of segments subsequent to the mutation contain the same mutation with different $3^{\prime}$ ends. In a second approach, SSCP is performed under two or more conditions. Typically, two temperatures are utilized, and occasionally, two temperatures with and without glycerol $(1,6)$ are used.

Recently, we reported that the pattern of SSCP varied markedly when HEPES was added to standard TBE buffer (7). The correlation coefficient $(r)$ between these two conditions was 0.46 . These results hint that sugar/base and sugar/sugar interactions are more important than secondary structure, which should be affected little, if at all, by the addition of HEPES.

Herein, we report a detailed analysis of gel matrix, running buffer, temperature and additive to search for a standard set of sensitive and complementary electrophoretic conditions for SSCP analysis. ddF was utilized to provide a very large sample of mutationcontaining segments for analysis. From the data, five conditions were chosen, and detection of virtually all mutationsSSCP (DOVAM-S) analysis was performed with $100 \%$ sensitivity in two blinded analyses.

\section{MATERIALS AND METHODS}

\section{ddF in Two Regions}

Polymerase chain reaction (PCR) was performed as described previously (4). A 785-bp region of exons B/C was amplified with primers F9(6094)-30D 
[number system (13)] and F9(6878)$27 \mathrm{U}$, and a $1-\mathrm{kb}$ region of exon $\mathrm{H}$ was amplified with primers F9(30646)-34D and F9(31645)-31U. The ddF reaction was performed with Thermo Sequenase ${ }^{\circledR}$ Radiolabeled Terminator Cycle Sequencing Kit (Amersham Pharmacia Biotech, Piscataway, NJ, USA). The sequencing mixture contained a total volume of $7 \mu \mathrm{L}: 16.7 \mathrm{mM}$ Tris-HCl, $\mathrm{pH}$ 9.5, $4.2 \mathrm{mM} \mathrm{MgCl}, 2.1 \mu \mathrm{M}$ of each dNTP, $0.021 \mu \mathrm{M}[\alpha-33 \mathrm{P}] \mathrm{ddCTP}$ or $[\alpha-$ $\left.{ }^{33} \mathrm{P}\right]$ ddGTP $\quad(1500 \mathrm{Ci} / \mathrm{mmol}, \quad 450$ $\mathrm{Ci} / \mathrm{mL}), 1.8 \mathrm{U}$ of Thermo Sequenase DNA Polymerase (Amersham Pharmacia Biotech), $200 \mathrm{ng}$ of purified PCR product and $0.1 \mu \mathrm{M}$ of sequencing primer F9(6272)-22D for exons B/C or F9(30851)-19D for exon H. Denaturation was at $95^{\circ} \mathrm{C}$ for $15 \mathrm{~s}$, annealing was at $55^{\circ} \mathrm{C}$ for $30 \mathrm{~s}$ and elongation was at $72^{\circ} \mathrm{C}$ for $1 \mathrm{~min}$ for a total of 30 cycles. Fifteen microliters of stop/loading buffer (50\% formamide, $7 \mathrm{M}$ urea, 2 mM EDTA, $0.05 \%$ bromophenol blue and $0.05 \%$ xylene cyanol) were added to each tube.

Twenty-nine mutations in exon $\mathrm{H}$ are utilized. The sample numbers and associated mutations correspond to the lane numbers for Figure 2, A and B: 1, C30875T; 2, A30897G; 3, $30905 \Delta \mathrm{G}$; 4, $30918 \Delta \mathrm{A} ; 5, \quad \mathrm{~A} 30918 \mathrm{G} ; 6$, C30928A; 7, A30929T; 8, T30930C; 9, C30935T; 10, T30936G; 11, T30945C; 12, G30950T; 13, $30969 \Delta \mathrm{GC} ; 14$, A30972G; 15, G30992A; 16, G31001T; 17, C31008T; 18, G31029A; 19, T31039A; 20, T31041C; 21,

Table 1. Exons and Primer Pairs for Blinded Analysis

\begin{tabular}{|c|c|}
\hline Exon & Primer Pair \\
\hline A & F9(-121)-20D and F9(49)-20U, and F9(9)-20D and F9(157)-21U \\
\hline $\mathrm{B} / \mathrm{C}$ & $\begin{array}{l}F 9(6242)-22 D \text { and F9(6536)-21U, F9(6476)-21D and F9(6736)-23U, and } \\
F 9(6242)-22 D \text { and F9(6736)-23U }\end{array}$ \\
\hline D & F9(10299)-20D and F9(10537)-22U \\
\hline $\mathrm{E}$ & F9(17633)-22D and F9(17843)-23U \\
\hline $\mathrm{F}$ & F9(20315)-21D and F9(20457)-24U, F9(20392)-21D and F9(20648)-21U \\
\hline G & F9(29991)-22D and F9(30219)-23U \\
\hline $\mathrm{H}$ & $\begin{array}{l}F 9(30746)-20 D \text { and } F 9(31026)-21 U, F 9(30969)-20 D \text { and } F 9(31167)-22 U \text {, } \\
F 9(31079)-21 D \text { and F9(31305)-21U, F9(31262)-20D and F9(31429)-20U, } \\
\text { F9(32637)-20D and F9(32827)-20U }\end{array}$ \\
\hline
\end{tabular}

G31047A; 22, G31052A; 23, C31077A; 24, C31091T; 25, C31118T; 26, T31127A; 27, C31140G; 28, T31152G; 29, G31203T.

\section{Blinded Analysis of DOVAM-S}

Blinded analysis was performed with 100 samples in the factor IX gene, including 50 samples with an unknown number of hemizygous mutations and 50 samples with an unknown number of heterozygous mutations. The eight exons and their splice sites were amplified by 15 pairs of primers (Table 1 ).

Each PCR was performed at $94^{\circ} \mathrm{C}$ for $15 \mathrm{~s}, 55^{\circ} \mathrm{C}$ for $30 \mathrm{~s}$ and $72^{\circ} \mathrm{C}$ for 1 min for 30 cycles. The PCR was hotstarted at $94^{\circ} \mathrm{C}$ for $10 \mathrm{~min}$ and ended with an additional $10 \mathrm{~min}$ at $72^{\circ} \mathrm{C}$. The
PCR mixture contained a total volume of $5 \mu \mathrm{L}: 50 \mathrm{mM} \mathrm{KCl}, 10 \mathrm{mM}$ Tris- $\mathrm{HCl}$, $\mathrm{pH} 8.3,2.5 \mathrm{mM} \mathrm{MgCl} 2,20 \mu \mathrm{M}$ of dATP and $200 \mu \mathrm{M}$ of each other dNTP, $0.6 \mu \mathrm{Ci}[\alpha-33 \mathrm{P}] \mathrm{dATP}(>2500 \mathrm{Ci} / \mathrm{mmol}$, $10 \mathrm{mCi} / \mathrm{mL}$; Amersham Pharmacia Biotech), $0.4 \mu \mathrm{M}$ of each primer, $0.2 \mathrm{U}$ of AmpliTaq Gold ${ }^{\mathrm{TM}}$ DNA Polymerase (PE Biosystems, Foster City, CA, USA), 200 ng genomic DNA. The PCRs were mixed with a fourfold volume of the stop buffer.

\section{Electrophoresis}

Non-denaturing gels $(45 \mathrm{~cm} \times 37.5$ $\mathrm{cm} \times 0.4 \mathrm{~mm}$ ) were electrophoresed by using a Poker Face ${ }^{\mathrm{TM}}$ SE 1500 Sequencing Apparatus (Hoefer Pharmacia Biotech, San Francisco, CA, USA) at

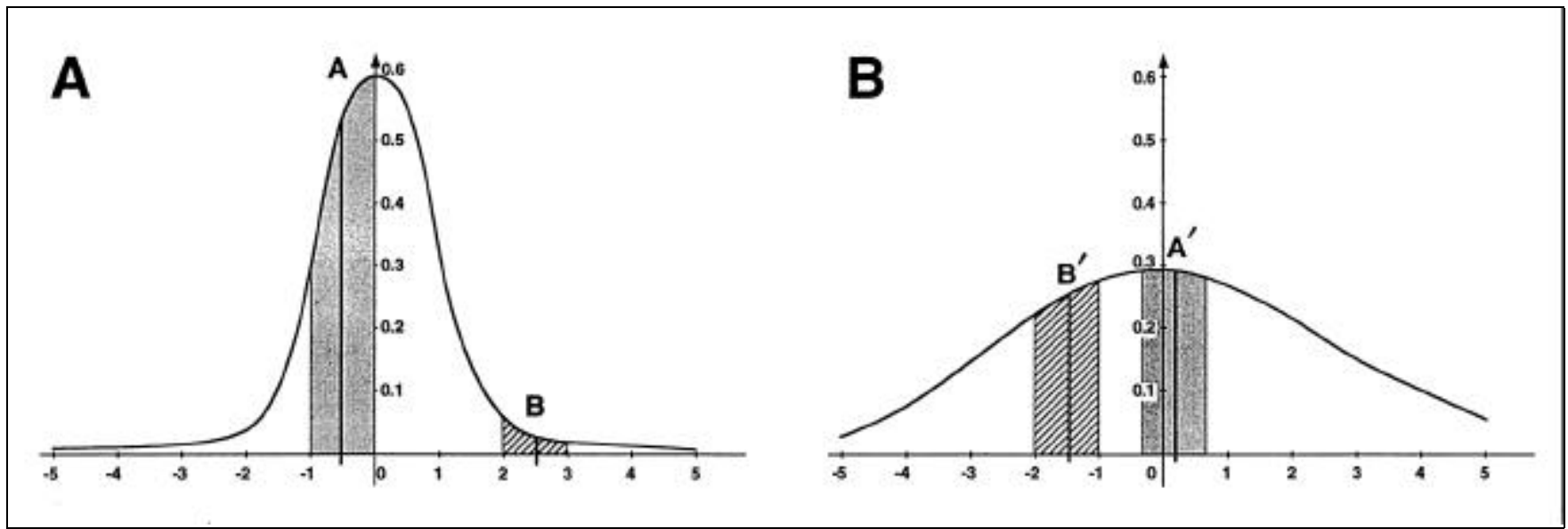

Figure 1. The principle of SSCP sensitivity. The x-axis represents segment mobility in units of band thicknesses from the average of mobilities. The mobility of two segments can be distinguished if they differ by a thickness of more than one-half of a band. The y-axis shows the relative frequencies of segments at a given mobility. The mobility of two hypothetical WT sequences are indicated by $\mathrm{A}^{\prime}$ and $\mathrm{B}^{\prime}$, respectively. 
A

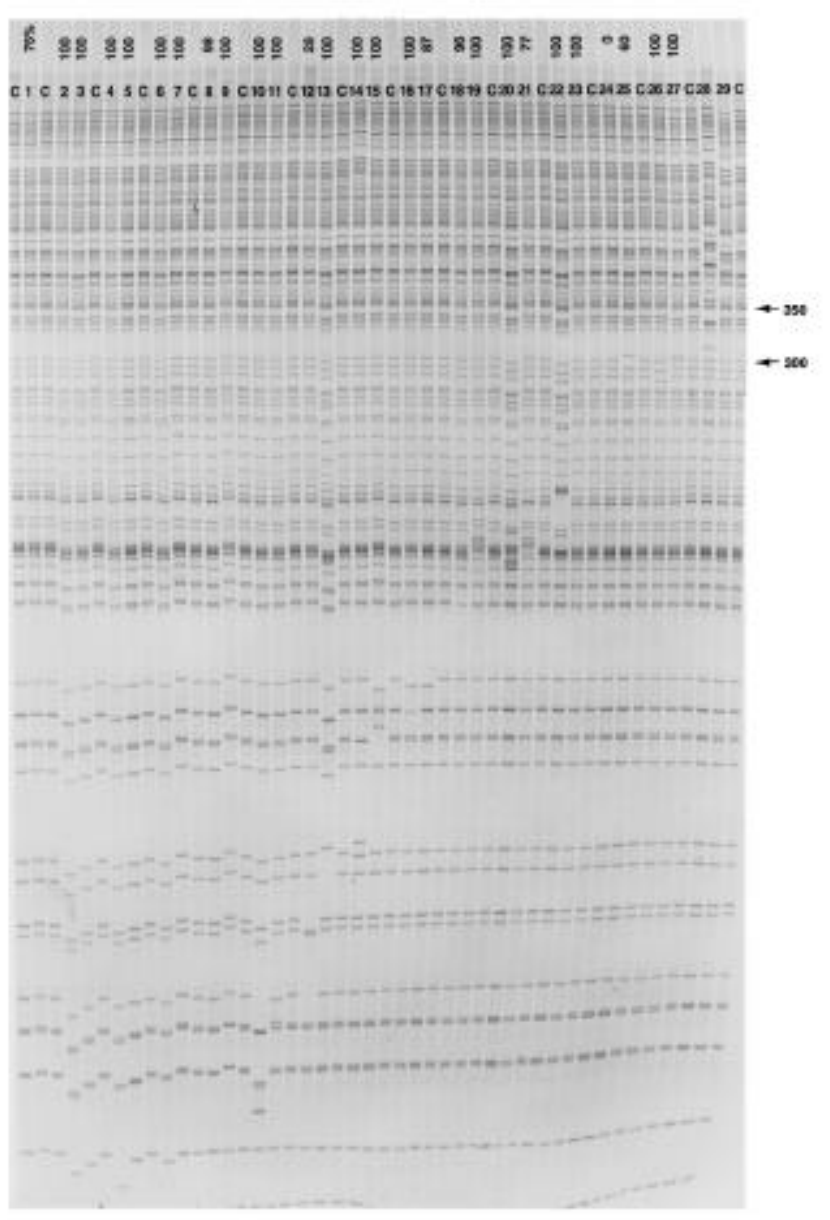

B

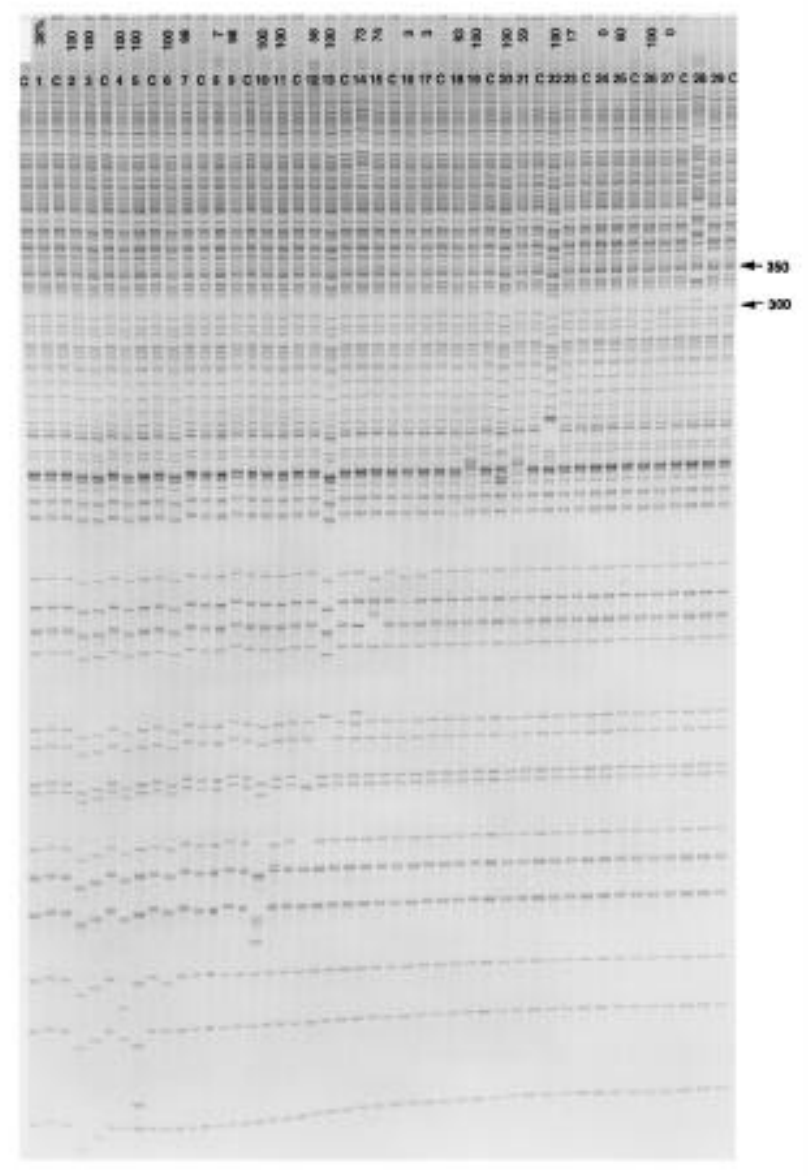

C

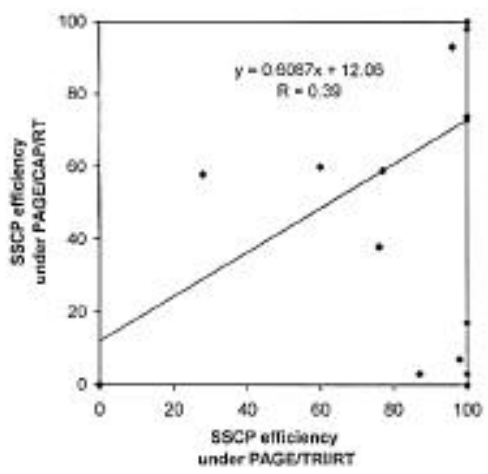

Figure 2. ddF in exon $\mathrm{H}$ : the effects of two buffers. ddF was performed under two different conditions for 29 patients with hemophilia $B$ and a WT sequence (lane C). The following conditions were compared: (A) PAGE/TRI/RT and (B) PAGE/CAP/RT. The location of segments of specific size was determined by the absence of a normal band or the presence of additional bands, which occurred in about half of the mutations (informative dideoxy component). These bands facilitated the analysis of the gel by finding the mobility of segments of certain defined sizes. Lane C: WT DNA. Lanes 1-28: 28 mutant samples from patients with hemophilia B (see Materials and Methods). The efficiency of the SSCP component is indicated on the gel top for each mutation analyzed. (C) Correlation of the SSCP efficiency. X-axis: the efficiency of the SSCP component (\%) for a specific mutation under the condition of PAGE/TRI/RT; Y-axis: corresponding efficiency $(\%)$ for the same mutation under the condition of PAGE/CAP/RT. For each mutation, the efficiency is the ratio of the number of shifted mutationcontaining segments to all the mutation-containing segments in the SSCP component. 


\section{Research Reports}

Table 2. Average Efficiency of the SSCP Component

\begin{tabular}{|c|c|c|c|c|c|c|c|}
\hline \multirow{3}{*}{$\begin{array}{l}\text { Genomic } \\
\text { Regionb }\end{array}$} & \multicolumn{7}{|c|}{ Average SSCP Efficiencya (\%) Under Each Condition } \\
\hline & 1 & 2 & 3 & 4 & 5 & 6 & 7 \\
\hline & $\begin{array}{l}\text { PAGE/TRI/ } \\
20^{\circ} \mathrm{C} \text { (III)c,d }\end{array}$ & $\begin{array}{l}\text { PAGE/CAP/ } \\
20^{\circ} \mathrm{C}\end{array}$ & $\begin{array}{l}\text { PAGE/CAP/ } \\
8^{\circ} \mathrm{C}(\mathrm{I})\end{array}$ & $\begin{array}{l}\text { HR/CAP/ } \\
20^{\circ} \mathrm{C}\end{array}$ & $\begin{array}{l}\text { HR/TBE/ } \\
20^{\circ} \mathrm{C}\end{array}$ & $\begin{array}{l}\mathrm{HR} / \mathrm{TRI} / \\
8^{\circ} \mathrm{C}(\mathrm{V})\end{array}$ & $\begin{array}{l}\text { HR/TBE/ } \\
8^{\circ} \mathrm{C} / \mathrm{Gly}(\mathrm{II})\end{array}$ \\
\hline Exon $\mathrm{H}$ & $89 d$ & 61 & 93 & 51 & 78 & 90 & 75 \\
\hline Exons B/C & 59 & 44 & 87 & 57 & 62 & 89 & 91 \\
\hline \multicolumn{8}{|c|}{$\begin{array}{l}\text { aApproximately } 1500 \text { segments with mutated sequence were analyzed under each condition. Per sample, the number of mu- } \\
\text { tated segments ranged from } 1-46 \text { segments. See text for definition of the efficiency. }\end{array}$} \\
\hline \multicolumn{8}{|c|}{$\begin{array}{l}\text { bThere are } 17 \text { substitution mutations in exon } \mathrm{H} \text { and } 16 \text { substitution mutations in exons } \mathrm{B} / \mathrm{C} \text {, which are selected due to low ef- } \\
\text { ficiency of the SSCP component. }\end{array}$} \\
\hline \multicolumn{8}{|c|}{$\begin{array}{l}\text { cPAGE }=10 \% \text { PAGEplus gel, HR }=10 \% \text { HR1000 gel; TRI }=30 \mathrm{mM} \text { triethanolamine/tricine buffer }(\mathrm{pH} 7.9) ; \mathrm{CAP}=30 \mathrm{mM} \\
\text { ethanolamine/CAPSO }(\mathrm{pH} 9.6) ; \text { Gly }=2.5 \% \text { glycerol. }\end{array}$} \\
\hline \multicolumn{8}{|c|}{$\begin{array}{l}\text { dRoman numerals designate the electrophoresis conditions selected for the blinded analysis of the factor IX gene. Condition } \\
\text { IV is not shown because it was tested in subsequent experiments. }\end{array}$} \\
\hline
\end{tabular}

12-W constant power or a Sequi-Gen ${ }^{\circledR}$ GT Sequencing Cell $(50 \mathrm{~cm} \times 38 \mathrm{~cm} \times$ $0.4 \mathrm{~mm}$; Bio-Rad, Hercules, CA, USA) at $15-\mathrm{W}$ constant power at $20^{\circ} \mathrm{C}$ or at $8^{\circ} \mathrm{C}$. Gel matrices included $10 \% \mathrm{MDE}^{\mathrm{TM}}$
Gel Solution (FMC BioProducts, Rockland, ME, USA), 10\% HR1000 (Genomyx, Foster City, CA, USA), 10\% PAGEplus (AMRESCO, Solon, OH, USA) and $10 \%$ Dcode $^{\mathrm{TM}}$ (Bio-Rad).
Running buffers included $50 \mathrm{mM}$ TBE (Tris-Boric acid, $\mathrm{pH}$ 8.3), $30 \mathrm{mM}$ CAP (ethanolamine/CAPSO, $\mathrm{pH}$ 9.6) and 30 $\mathrm{mM}$ TRI (triethanolamine/tricine, $\mathrm{pH}$ 7.9). Additives were glycerol, urea, 


\section{Research Reports}

Table 3. Correlation Coefficients ( $r$ ) of the Efficiencies of Mutation Detection in Exons H and B/C by Pairs of SSCP Conditions

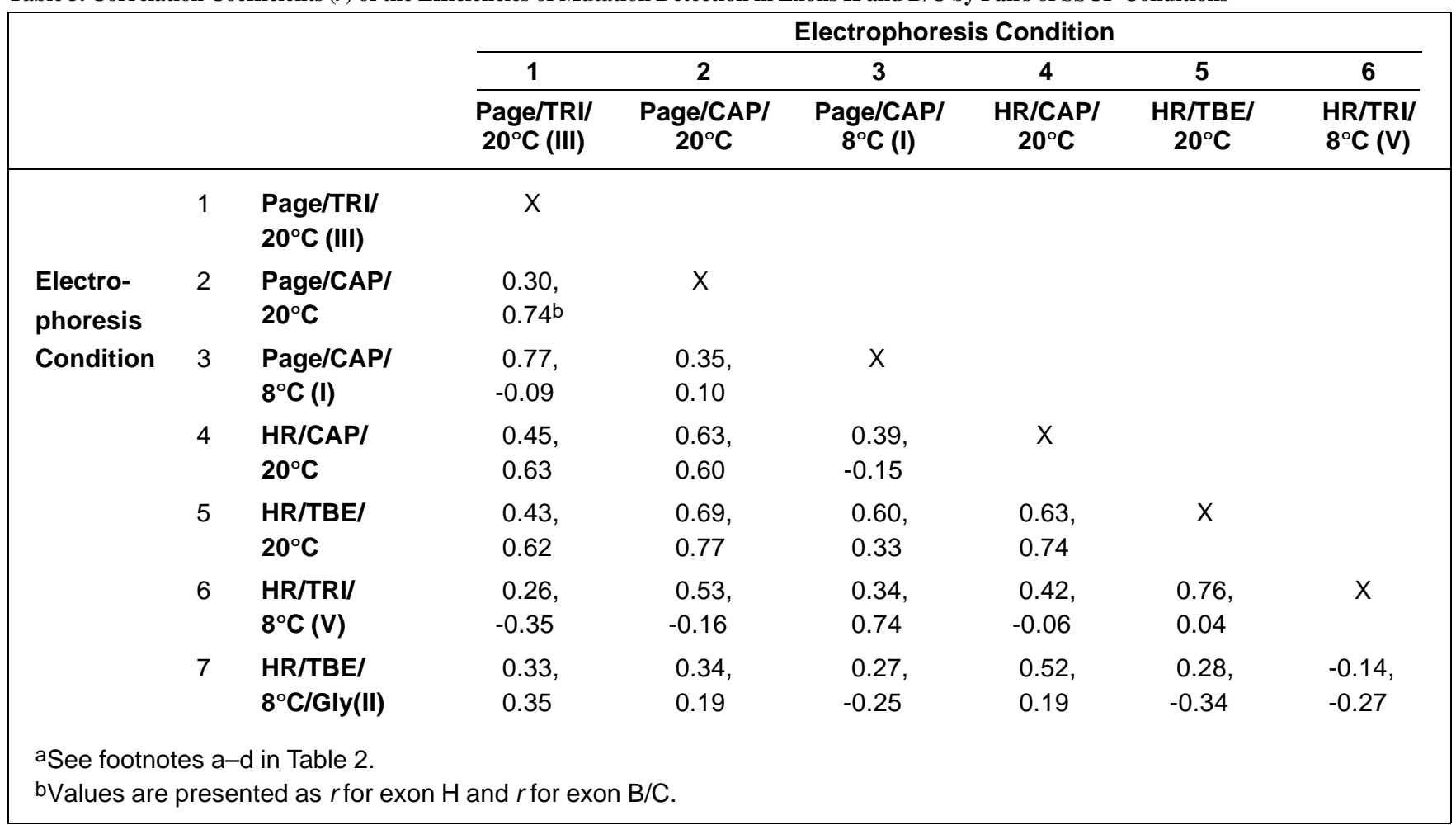

Table 4. Summary of Blinded Analysis

A. Individual SSCP Sensitivity

\begin{tabular}{lcccc}
\multicolumn{5}{c}{ Individual Condition } \\
\hline $\mathrm{PAGE} / \mathrm{CAP} / 8^{\circ} \mathrm{C}$ (I) & $\mathrm{HR} / \mathrm{TBE} / 8^{\circ} \mathrm{C} /$ & $\mathrm{PAGE} / \mathrm{TRI} / 20^{\circ} \mathrm{C}$ & $\mathrm{PAGE} / \mathrm{TBE} / 20^{\circ} \mathrm{C} /$ & $\mathrm{HR} / \mathrm{TRI} / 8^{\circ} \mathrm{C}(\mathrm{V})$ \\
& $2.5 \% \mathrm{Gly}$ (II) & (III) & $5 \% \mathrm{Gly}$ (IV) &
\end{tabular}

$\begin{array}{llllll}\text { Sensitivitya }(\%) & 79 & 87 & 65 & 89 & 65\end{array}$

B. Observed Joint SSCP Sensitivities

Observed Sensitivity for all Possible Groups of Conditions ${ }^{\mathrm{b}}(\%)$

\begin{tabular}{lcccc|} 
& \multicolumn{4}{c}{ Observed Sensitivity for all Possible Groups of Conditions $\mathbf{~}^{\mathbf{b}}$ \%) } \\
\cline { 2 - 5 } & $\begin{array}{c}\text { 2 joint conditions } \\
\text { (10 sets) }\end{array}$ & $\begin{array}{c}\text { 3 joint conditions } \\
\text { (10 sets) }\end{array}$ & $\begin{array}{c}\text { 4 joint conditions } \\
\text { (5 sets) }\end{array}$ & $\begin{array}{c}\mathbf{5} \text { joint conditions } \\
\text { (1 set) }\end{array}$ \\
\hline Group with best score (\%) & 95 & 100 & 100 & 100 \\
Group with worse score (\%) & 85 & 89 & 94 & 100
\end{tabular}

C. The Distribution of Hits Under All the Five Conditions

The Number of Hits for a Given Mutation

\begin{tabular}{lllllll} 
& 0 & 1 & 2 & 3 & 4 & 5 \\
\hline Mutations (\%) & 0 & 10 & 8 & 8 & 30 & 44
\end{tabular}

aThe individual sensitivity was calculated under each set of conditions, and each sense and antisense pair of segments were taken as a unit for calculation of sensitivity.

bThe observed joint sensitivities (\%) were calculated under two, three, four and five sets of conditions, which had ten, ten, five and one possible combinations, respectively. The best scores were obtained under two conditions of II and IV; under three conditions of II and IV and any of conditions I, III and V; under four conditions of II and IV and any two of conditions I, III and V. The worst scores were obtained under two conditions of III and V; under three conditions of III and V and I; under four conditions of III and V and I and IV. 
Resolver Gold ${ }^{\mathrm{TM}}$ and polyethylene glycol (PEG). After a pre-electrophoresis for $30 \mathrm{~min}, 1.5 \mu \mathrm{L}$ of sample was loaded and electrophoresed for $6-16 \mathrm{~h}$. The gel was dried and autoradiographed with Kodak BioMax MR film (Scientific Imaging Systems [Eastman Kodak], New Haven, CT, USA]).

\section{Gel Analysis}

On the ddF gel, an informative dideoxy component was easily detected by a missing segment or an extra segment. The mutation-containing segments showing altered mobilities in the SSCP component were scored and compared with a WT control. In the blinded analysis, 30 single-stranded segments (15 double-stranded PCR products), covering the eight exons were scored by comparison with their neighbors. Unequivocal mobility changes were scored. Typically, a migration change of $1 / 2$ band width on the upper part of the gel or $1 / 4$ band width on the lower part was the limit of resolution.

\section{RESULTS AND DISCUSSION}

\section{Searching for Sensitive and Complementary Conditions}

ddF gels were utilized to efficiently explore the SSCP sensitivity of different conditions. For a given mutation, the efficiency of the SSCP component is the percentage of shifted mutation-containing segments. The segments of the SSCP components of up to 300 bases were scored. The number of the mutation-containing segments varied from $1-46$, depending on the location of the mutation. The efficiency of the SSCP component was utilized as a measure of the likelihood that a given mutation would show a detectable shift in mobility under a given condition. For the few samples in which the number of mutation-containing segments were low (less than 13), the results were generally similar when the analysis was extended to include segments up to 350 nucleotides.

ddF gels were performed under two conditions (PAGEplus/TRI/room temperature $[\mathrm{RT}]$ and PAGEplus/CAP/RT; Figure 2, A and B). For exon $\mathrm{H}$, the average SSCP efficiencies for the 24 substitutions analyzed were $91 \%$ and $72 \%$ for the two conditions, respectively. The efficiencies for individual mutations varied with the conditions; i.e., the efficiency for sample 6 was $98 \%$ and $7 \%$, respectively, and the efficiency for sample 13 was $100 \%$ and $3 \%$, respectively. Of the 24 samples with singlebase substitutions, in Figure 2, A and B, respectively, $4 \%$ and $25 \%$ had efficiencies of $\langle 20 \%$; $17 \%$ and $25 \%$ had efficiencies from $21 \%-80 \%$; and $79 \%$ and $50 \%$ had efficiencies $>81 \%$. The efficiencies under the two conditions for each mutation in exon $\mathrm{H}$ were plotted (Figure 2C) and were poorly correlated $(r=0.39$, and the $99 \%$ confidence interval overlaps with zero).

Because the efficiency of the SSCP component under standard conditions is low in exon $\mathrm{B} / \mathrm{C}$ but is high in exon $\mathrm{H}$, 17 selected single-base substitutions in exon $\mathrm{H}$ and 16 selected single-base substitutions in exons $\mathrm{B} / \mathrm{C}$ were chosen for further testing. A variety of electrophoresis conditions were tested, which included gel matrices of MDE, HR1000, PAGEplus and Dcode, running buffers of TBE ( $\mathrm{pH}$ 8.3), CAP, which is a high $\mathrm{pH}$ buffer ( $\mathrm{pH}$ 9.6), and TRI, which is a medium $\mathrm{pH}$ buffer ( $\mathrm{pH}$ 7.9); additives of glycerol, urea, Resolver Gold and PEG; and temperatures at $20^{\circ}$ and $8^{\circ} \mathrm{C}$. Under each condition, the efficiency of the SSCP component was scored for each mutation and for each region.

The average efficiency of the SSCP component for the 17 mutations from exon $\mathrm{H}$ and the 16 mutations from exon $\mathrm{B} / \mathrm{C}$ was utilized to estimate the overall sensitivity of seven conditions (Table 2 ). The averages are derived from analysis of about 1500 mutation-containing segments. The average efficiencies varied with the regions analyzed and the conditions. Correlation coefficients also varied with the regions analyzed and the conditions (Table 3 ). The effects of changing only buffer (compare conditions 1 and 2 and 4 and 5), of only temperature (compare conditions 2 and 3), of only matrix (compare conditions 2 and 4), of both temperature and glycerol (compare conditions 5 and 7) and of both buffer and glycerol (compare conditions 6 and 7), are among the changes that can be assessed in Table 3. Some of the correlation coefficients were negative, implying that given samples of low efficiency 
under one condition were preferentially of higher efficiency under the second condition. Glycerol and temperature seemed to be the factors that produced the greatest changes in mobility pattern.

Five conditions for DOVAM-S were selected after analysis of 22 conditions (data not shown). Tables 2 and 3 show four of those five conditions (see Roman numerals). These conditions were selected as having both reasonably high average SSCP efficiencies (Table 2) and low correlations or negative correlations for both exons $\mathrm{H}$ and $\mathrm{B} / \mathrm{C}$ (Table 3).

\section{Blinded Analysis of DOVAM-S}

The five selected conditions were tested by a blinded analysis in which the eight exons and associated splice junctions of the factor $I X$ gene were scanned in one lane (Table 4A). Fifty hemizygous mutant or WT samples and 50 additional heterozygous mutant or WT samples were analyzed. Fifteen PCR segments of the factor IX gene were amplified, ranging in size from 143-295 nt.
In total, all 84 single-base substitutions were detected throughout all the 15 PCR segments by DOVAM-S. In retrospect, all of the mutations could have been detected by a combination of the three best conditions (Table 4B). However, the idiosyncratic nature of SSCP dictates that one cannot predict, a priori, which combinations of conditions will be the best. There is sufficient redundancy, such that the worst score of combination of conditions required the five conditions. Almost $75 \%$ of the mutations were detected in at least four of the five conditions. Ten percent of the mutations were detected with only one of the five conditions (Table 4C).

More data are required to determine whether one or a few percent of mutations might be missed when DOVAM-S is applied to other genes. However, past experience with $\mathrm{ddF}$ and restriction endonuclease fingerprinting (REF) and with the very large statistical sample size that underlies this analysis (1500 mutation-containing segments per condition) suggest that the sensitivity of DOVAM$\mathrm{S}$ with the present conditions will be very high, perhaps $99 \%$ or greater. A prospective analysis of the factor VIII gene in patients with hemophilia A confirms this. Mutations were found in 85 of 94 patient samples (F.K. Fujimura et al.; unpublished). The remaining nine samples were sequenced by the ABI Model 377 DNA Fluorescent Sequencer (PE Biosystems), and no sequence changes were identified. At least one of the samples without mutations was subsequently found to be misdiagnosed or to have an inversion mutation that occurred outside of the scanned regions.

Genes with high GC content may require the addition of urea to prevent the segments from smearing on the SSCP gels. The data suggest that the sensitivity will remain high as long as the urea concentration is close to the minimum needed to prevent smearing (5). Note that higher concentrations of urea may produce very sharp bands, resembling those in sequence gels; however, SSCP sensitivity decreases.

\section{REFERENCES}

1.Glavac, D. and M. Dean. 1993. Optimization of the single-strand conformation polymorphism (SSCP) technique for detection of point mutations. Hum. Mutat. 2:404-414.

2.Hayashi, K. and D.W. Yandell. 1993. How sensitive is PCR-SSCP? Hum. Mutat. 2:338346.

3.Hongo, T., G.S. Buzard, R.J. Calvert and C.M. Weghorst. 1993. 'Cold SSCP': a simple, rapid and non-radioactive method for optimized single-strand conformation polymorphism analyses. Nucleic Acids Res. 21:36373642 .

4.Liu, Q., J. Feng and S.S. Sommer. 1996. Bidirectional dideoxy fingerprinting (Bi-ddF): a rapid method for quantitative detection of regions of 300-600 bp. Hum. Mol. Genet. 5:107114.

5.Liu, Q., J. Feng and S.S. Sommer. 1997. In a blinded analysis, restriction endonuclease fingerprinting detects all the mutations in a $1.9-\mathrm{kb}$ segment. BioTechniques 23:836-839.

6.Liu, Q. and S.S. Sommer. 1994. Parameters affecting the sensitivities of dideoxy fingerprinting and SSCP. PCR Methods Appl. 4:97-108.

7.Liu, Q. and S.S. Sommer. 1998. The SSCP phenomenon: addition of HEPES buffer dramatically affects electrophoretic mobility. BioTechniques 25:50-56.

8.Michaud, J., L.C. Brody, G. Steel, G. Fontaine, L.S. Martin, D. Valle and G. Mitchell. 1992. Strand-separating conformational polymorphism analysis: efficacy of detection of point mutations in the human ornithine $\delta$-aminotransferase gene. Genomics 13:389-394.

9.Sarkar, G., H. Yoon and S.S. Sommer. 1992. Dideoxy fingerprinting (ddF): a rapid and efficient screen for the presence of mutations. Genomics 13:441-443.

10.Sarkar, G., H. Yoon and S.S. Sommer. 1992. Screening for mutations by RNA single-strand conformation polymorphism (rSSCP): comparison with DNA-SSCP. Nucleic Acids Res. 20:871-878.

11.Sheffield, V.C., J.S. Beck, A.E. Kwitek, D.W. Sandstrom and E.M. Stone. 1993. The sensitivity of single-strand conformation polymorphism analysis for the detection of single base substitutions. Genomics 16:325-332.

12.Takahashi-Fujii, A., Y. Ishino, A. Shimada and I. Kato. 1993. Practical application of fluorescence-based image analyzer for PCR single-stranded conformation polymorphism analysis used in detection of multiple point mutations. PCR Methods Appl. 2:323-327.

13.Yoshitake, S., B.G. Schach, D.C. Foster, E.W. Davie and K. Kurachi. 1985. Nucleotide sequence of the gene for human factor IX (antihemophilic factor B). Biochemistry 24:37363750 .

Received 26 October 1998; accepted 20 January 1999.

Address correspondence to:

Dr. Steve S. Sommer

Director, Departments of Molecular Genetics and Molecular Diagnosis

City of Hope National Medical Center

1500 East Duarte Road

Duarte, CA 91010-3000, USA

Internet: ssommer@coh.org 